\title{
Do European agri-environment measures help reduce herbicide use? Evidence from viticulture in France *
}

\author{
Laure Kuhfuss $^{\dagger}$ Julie Subervie $^{\ddagger}$
}

\begin{abstract}
Agri-environmental Schemes (AES) are a central component of the European environmental policy, but few of these schemes have been carefully evaluated and doubts are often expressed about their effectiveness. We use original data collected from winegrowers who participated in an AES targeting non-point source pollution from herbicides in 2011 and 2012 in the South region of France. Using the variation in the implementation of the scheme across time and space and a matching approach, we show that the quantity of herbicides used by participants in the scheme in 2011 ranges from 38 to 53 percent below what they would have used without the scheme and this percentage is between 42 to 50 percent in 2012. Further, our results suggest that least demanding AES options are effective in avoiding pollution peaks when weed pressure is high, whereas more demanding AES options guarantee an overall reduction in herbicide use, even during relatively easy farming years in which less weed pressure is experienced.
\end{abstract}

Key words: Payments for Environmental Services, agri-environmental scheme, water quality, nonpoint source pollution, herbicides, pesticides, treatment effect.

JEL: Q15, Q18, Q25, Q28, Q53.

\footnotetext{
${ }^{*}$ Funding for this research was provided by the French Agency for Water and Aquatic Environments (ONEMA) as part of the 2011 call for projects 'Changer les pratiques agricoles pour preserver les services ecosystemiques' supporting the implementation of the French National Action plan Ecophyto 2018. Part of the data used in the study were made available by the French Department of Statistics of the Ministry of Agriculture (SSP) via the Secure Data Access Centre (CASD). This research would not have been possible without the full cooperation of the Regional Directorate for Food, Agriculture and Forestry (DRAAF) and the AES site operators from the LanguedocRoussillon region. We are particularly grateful to M. Schill, A. Boscher, M. Comat, J. Druais-Levasseur, C. Garrel, L. Gaillard, M.D. Gras, P.A. Guérin, L.E. Lecoq, O. Liet, M. Lobre, S. Maret and J. Oustric. We want to thank Marc Voltz (INRA) for his invaluable comments and suggestions. Funding was also made available by the Scottish Government Research Program (RESAS) for the preparation of this manuscript. We also thank seminar participants at the French National Institute for Agricultural Research, Toulouse School of Economics, the School of Geography and Sustainable Development of the University of St Andrews and colleagues from the SEGS group who reviewed the paper at the James Hutton Institute. All remaining errors are obviously our own.

${ }^{\dagger}$ University of St Andrews, School of Geography and Sustainable Development, St Andrews - United Kingdom; The James Hutton Institute, Social, Economic and Geographical Sciences Group, Dundee - United Kingdom lk38@st-andrews.ac.uk

${ }^{+}$French National Institute for Agricultural Research (INRA) and Center for Environmental Economics - Montpellier (CEE-M), Montpellier - France. subervie@supagro.inra.fr
} 


\section{Introduction}

In the mid-1980s, increasing concern over the environmental impact of agriculture led to the introduction of agri-environmental schemes (AESs) in the European Union. AESs offer payments to farmers who voluntarily accept to adopt pro-environmental practices, and constitute a central component of the European Common Agricultural Policy (CAP) 11 However, doubts are often expressed about the effectiveness of these schemes. Indeed, because AESs are voluntary schemes whose requirements and per-hectare payments are generally uniform for all farmers, the potential for adverse selection is high (Fraser, 2009: Chabé-Ferret and Subervie, 2013). In the extreme case in which an AES only attracts farmers who would have behaved the same way in the absence of payment, the additionality of the AES is nil.

Despite widespread interest and investment in AESs (Uthes and Matzdorf (2013); Udagawa, Hodge, and Reader (2014)), few schemes have been thoroughly evaluated. Chabé-Ferret and Subervie (2013) demonstrate the additionality of French AESs that impose strong requirements, such as the AES subsidizing conversion to organic farming, with large effects. On the contrary, the authors find that for AESs with modest aims, such as the AES only requiring farmers to add one crop to the rotation, these additional effects are very limited.. Pufahl and Weiss (2009) show that, overall, benefiting from AESs may significantly decrease the use of agrochemicals and increase grassland area in Germany. Arata and Sckokai (2016) consider as well the overall impact of European AESs on a range of indicators, such as the per hectare expenditures on fertilizers and crop protection, the share of grassland, and the number of crops grown on the farm. They find that, overall, AESs affect more heavily the production choices of participants whose farm income rely on agri-environmental payments by more than five percent. Despite the increasing literature on the effectiveness of AESs, to the best of our knowledge there are no studies that evaluate the effectiveness of AESs specifically targeting the use of pesticides. This article aims at filling this gap.

Contamination by pesticides from agriculture is a source of water quality degradation in several countries in the European Union according to Eurostat $]^{2}$ This occurs when pesticides used in fields are transported by runoff and deposited into lakes, rivers, wetlands, coastal waters, and underground sources of drinking water. These pollutants are of increasing concern because of their potential impacts on the environment, wildlife, and human health. During the 2007-2014 CAP programming period, AESs have been used in France to fulfill the objectives of the European Union water framework directive. Therefore, AESs have been implemented to reduce contamination by pesticides in catchment areas where water quality improvement has been identified as a priority from 2007. Farmers participating in these AESs commit to reduce their use of pesticides for five years in exchange for a predefined annual payment. These

\footnotetext{
${ }^{1}$ The European Agricultural Fund for Rural Development (EAFRD) has been allocated a budget of EUR 96.3 billion for the period 2007-2013 (20\% of the funds dedicated to the CAP), of which EUR 1.8 billion has been allocated to French AESs. Figures are available on the site of the French Ministry of Agriculture

${ }^{2}$ Figures are available on the site Eurostat provided by the European Commission.
} 
schemes are routinely monitored and evaluated on the basis of participation rates, spatial coverage and budget spending. However, they have received little attention with respect to their actual impact on agricultural practices. To answer this question, we focus on one emblematic case study: herbicide use in South of France vineyards.

Of all cropping systems in France, wine growing is the one that uses the pesticides the most, with an average application of 16 phytosanitary treatments per hectare in 2010 (Agreste, 2012). Among the pesticides used by winegrowers, herbicides are the most commonly detected in the ground and surface waters in South of France. Given the extent of winegrowing and its reliance on herbicides ${ }^{3}$ incentivizing winegrowers to reduce their use of herbicides is a major challenge. This challenge has been addressed by the implementation of an AES called the "territorialized AES" that includes several options for herbicide use reduction. The objective of the present study is to estimate the additional effect of these options on the quantity of herbicides used by winegrowers who entered the scheme in the first four years of its implementation (2010-2013) in Languedoc-Roussillon, a region in Southern France.

The main concern when evaluating the impact of an AES arises from the fact that participants in the AES self-select into the scheme given its voluntary nature. To deal with this issue, we use the variation in the administrative eligibility of farmers to the scheme across time and space, an identification strategy commonly used in the microeconomic impact analysis literature (see for example Bruhn (2013), Aker (2010), Jensen (2007), Galiani, Gertler, and Schargrodsky (2005)). In practice, we compare the use of herbicides of participants in the AES to that of non-participants displaying identical observable characteristics and who became participants once administratively eligible. We use a matching approach to estimate the average treatment effect on the treated (ATT), i.e. the impact of participating into the AES in 2011 and 2012. Specifically, we estimate the ATT for a given year through a comparison of the average use of herbicides of participants located on already-approved catchment areas with the average use of herbicides of, otherwise similar, future-participants located on catchments where the AES was not yet implemented. For this, we use data on herbicide use collected by local catchment operators from 153 winegrowers, who represent approximately 76 percent of the total area under contract in the region in 2013. Our matching procedure is based on a large set of pre-treatment individual-specific characteristics provided by the French Agricultural Census.

We first evaluate the overall impact of all AES options targeting herbicide use in the region. We find that the quantity of herbicides used by participants in the scheme in 2011 ranges from 38 to 53 percent below what they would have used without the scheme, and from 42 to 50 percent in 2012. All our results are robust to various matching estimators. We moreover perform a sensitivity test that provides support to our findings. Our results are also robust to the exclusion of participants in the most stringent measure (the organic farming option) which could have been suspected of driving the overall results. Our findings also hold when focusing on

\footnotetext{
${ }^{3}$ Growing wine grapes indeed requires controlling competitive weeds in order to ensure adequate levels of production.
} 
a sub-region of the study area, therefore accounting for spatial heterogeneity. We moreover evaluate the impact associated with the least stringent measure, which is also the most popular (the "zero herbicide between the rows" option). Our results show that the impact of this option alone was statistically significant in 2011 but not in 2012. This suggests that least demanding AES options are effective in avoiding pollution peaks when weed pressure is high (as in 2011), whereas more demanding AES options guarantee an overall reduction in herbicide use even during relatively easy farming years in which less weed pressure is experienced (as in 2012). The remainder of this article is organized as follows. We first present the scheme under study and the institutional rules governing the timing of its implementation in Section 2 . We present the data used in Section 3 , then the identification strategy in Section 4 . Thereafter we present and discuss the results of the overall scheme evaluation and of one specific option the so-called "zero herbicides between the vine rows" in Section 5 . This section also provides a sensitivity analysis and various robustness checks. Section 6 concludes.

\section{AES targeting herbicide use}

Languedoc-Roussillon contains more vineyards than any other region in France, covering some 236,500 ha and constituting 30 percent of the nation's vineyards. Two out of every three farms in the region grow wine grapes (Agreste, 2011). The AES options offered to winegrowers in this region between 2010 and 2013 focused exclusively on the reduction of herbicides use. These measures target the most environmentally-sensitive catchments and are implemented by local operators in 29 catchments in the Languedoc-Roussillon region, most of which exhibit levels of herbicide residues exceeding the regulatory limit. Figure 1 shows the areas in the LanguedocRoussillon region where water quality improvement has been identified as a priority by public authorities and therefore where farmers were offered to participate in the AES.

This AES relies on 5-year contracts, to which farmers apply voluntarily. The payments offered to participants are the same for all participants and are calculated with the view to compensate any income forgone and additional costs associated with the contracted farming practices. In practice, the income foregone calculation is based on a national price scale and accounts for an estimate of the increased workforce and equipment hire for alternative practices to chemical weeding, taking into account reduced spending on herbicides. The payments also cover the costs of annual on-farm follow-up visits by a certified technician. Farmers are able to choose one or more of four possible AES options: convert to organic wine growing for $350 €$ per hectare, eliminate all herbicide use for $243 €$ per hectare, reduce herbicides use by 40 percent of the regional standard for $141 €$ per hectare, and eliminate herbicide use between vine rows only for $165 €$ per hectare.

It is worth mentioning that AES implementation by local operators in priority areas required many administrative procedures that ended up delaying the availability of the scheme to farmers in some cases. As a first requirement, a hydro-geological diagnostic had to be established 
for each priority catchment in order to assess its vulnerability and accurately define the limits of the area targeted by the AES. An official decree then had to approve this delimitation. Next, a local operator was nominated to design an agri-environmental project based on a second diagnostic. This second diagnostic aimed to identify the current farming practices in use at the catchment in order to best adapt the proposed options to the needs of local farmers. For each farm sector in the catchment, the AES operator had to choose two options from a national menu that could be offered to farmers in the catchment. As the last requirement, the final scheme had to be validated by a regional committee meeting once a year. After this process was complete, the local operator was then in charge of promoting the AES to farmers. Finally, farmers willing to participate had to send in an application form by the 15th of May, i.e. 15th of May 2011 for those who decided to enter the scheme in 2011 and 15th of May 2012 for those who decided to enter the scheme in 2012..

The time needed to implement these steps was highly heterogeneous between catchment areas. Consequently, the different areas became eligible to participate in the AES at different dates. Information we obtained from local operators during the data collection suggest that the time required for AES implementation was likely related to the nature of the local operator themselves. In what follows, we make use of this exogenous variation in the timing of the AES implementation to estimate the impact of farmer's participation into the scheme on the quantity of herbicides used.

\section{Data}

\subsection{Sample}

Our sample includes a total number of 153 winegrowers who entered the scheme between 2010 and 2013 and who are located in three counties of the Languedoc Roussillon region. Our database includes 3,630 ha of the 4,802 ha of vineyards engaged in the scheme between 2010 and 2013, or approximately 76 percent $\square^{4}$ the total area under contract in the study area in 2013 according to the French Paying Agency ${ }_{5}^{5}$

Table 1 provides the area under contract in the sample, by AES option and by start year. The last row indicates that the total area under contract is much larger in 2012 than in other years. The reason for this is that a large number of territories, some very large, have become eligible to the AES that year. The last column shows that the most popular option in our sample is the one requiring elimination of herbicide use between the vine rows only, with no limits on the quantity of herbicides used underneath the vine rows. It represents about 79 percent of the total area covered by the sample. This proportion is very close to the actual regional take-up, 72 percent

\footnotetext{
${ }^{4}$ Data for the remaining 24 percent was not available due to either delays in farms' annuals diagnostics or unreadable handwritten documents

${ }^{5}$ The French Paying Agency is in charge of implementing rural development programmes under the responsibility of the Ministry of Agriculture. Figures are available on the site of the Rural Development Observatory.
} 
of engaged areas in the region according to the French Paying Agency. In viticulture, the main alternatives to using herbicides for weed control are mechanical methods such as tillage, managed grass, and mowing. They might be more time-consuming but do not affect yields. However, mechanized weeding under vine rows requires specific investments, and farmers willing to reduce their use of herbicides without these further investments usually combine the use of mechanical alternatives between the rows with chemical weeding underneath the rows. That is why the most popular option is the one requiring suppressing herbicide use between the vine rows only.

\subsection{Herbicide Use}

Every farmer willing to participate in the scheme was required to undergo a diagnosis of his farm by a certified technician. As part of this diagnosis, information on the quantity of herbicides used during the previous farming season was collected for each plot on the farm. This appraisal was conducted every year during the entire period of the AES through an annual follow-up for the enrolled plots. We collected both the initial diagnosis as well as the follow-up documents held by the catchment operators for most farmers who entered the scheme between 2010 and 2013.

From these data, we were able to calculate the quantity of herbicides used by winegrowers on the plots under contract, as measured through the Treatment Frequency Index (TFI). This index represents the number of so-called reference doses of herbicides applied during a farming year (Pingault et al. 2009). The reference dose is often considered the normal dose, as it corresponds to the efficient dose of a product for a specific culture and pest:

$$
\mathrm{TFI}=\frac{\text { treated area }}{\text { total area }} * \frac{\text { dose used }}{\text { reference dose }}
$$

For example, if the reference dose of an herbicide is spread over the entire area of a plot, then the TFI of the plot equals one. If the herbicide is spread at its reference dose but only under the vine rows, the TFI of the plot equals one third, because the space between vine rows is roughly twice as wide as the vine row itself.

Although every participant in the scheme was required to provide detailed information on the quantity of herbicides used each year to the catchment operator, some follow-up documents were not available at the time we met the catchment operators. Thus, some observations are missing in the database. Moreover, even when the follow-up document was available, we were not able to calculate the quantity of herbicides used in some cases because the information was incomplete. In the end, we were able to construct the TFI in 2011 for 123 winegrowers who had entered the scheme between 2010 and 2012, and the TFI in 2012 for 138 winegrowers who had entered the scheme between 2010 and 2013. 5 Note that our sample does not include

\footnotetext{
${ }^{6}$ We also obtained data on the quantity of herbicides used in 2010 for farmers who entered the scheme in 2010 or 2011, and data on the quantity of herbicides used in 2013 for some farmers who entered the scheme between
} 
farmers who never participated in the AES. This is simply because data about these practices are available only if the farmer participate into the AESs. Indeed, the quantity of herbicides used by winegrowers is private data, and even if most winegrowers keep records of the treatments they apply, they are under no legal obligation to provide this information unless they participate in AESs.

\subsection{Winegrowers' characteristics}

We then matched the herbicide use data to the French Agricultural Census that was conducted in 2010 by the Department of Statistics of the French Ministry of Agriculture on the basis of a common identifier (the farm business identification number). This census contains a detailed description of every French farmer during the farming year 2009-2010, i.e. before the first wave of participation in the AES. The French Agricultural Census provides a range of characteristics likely to influence the decision to enter an AES, which includes: agricultural education, agricultural training, general education, spouse's main activity, vineyard surface area in hectares and as a share of the Utilized Agricultural Area (UAA), on-farm labour (in annual work units), production (in hectoliters per hectare), production under protected designation of origin (as a share of the UAA), vinification in particular cellar (as a share of the production), Protected Denomination of Origin (as a share of the production), irrigated land (as a share of the UAA), ownership (as a share of the UAA), the average topographic slope of the municipality where the farm is located, and the proportion of UAA cultivated without herbicides. We provide mean values of these variables for each group selected in the impact analysis thereafter (see Tables 2 and5in Section 5.1), and use these variables as covariates in all matching procedures below.

\section{Identification Strategy}

\subsection{Parameter of interest}

The parameter we aim to estimate is the average causal effect of the AES on the amount of herbicides used by winegrowers who actually participated in the AES, the so-called Average Treatment effect on the Treated (ATT):

$$
\mathrm{ATT}=E\left[Y^{1}-Y^{0} \mid \mathrm{AES}=1\right]=\underbrace{E\left(Y^{1} \mid \mathrm{AES}=1\right)}_{\text {observable }}-\underbrace{E\left(Y^{0} \mid \mathrm{AES}=1\right)}_{\text {unobservable }}
$$

where $Y^{1}$ is the TFI in the presence of the AES, $Y^{0}$ is the TFI in the absence of the scheme and $A E S$ is the treatment variable, a dummy variable that takes the value 1 if the winegrower is participating to the scheme and 0 otherwise. The average level of herbicide that would have been

2010 and 2013, but the resulting sample size and the proportion of farmers who can be considered as treated in our framework are too small to allow us to estimate the impact of the AES in 2010 or 2013. 
used by participants, had they not participated in the AES, $E\left(Y^{0} \mid \mathrm{AES}=1\right)$, is unobservable to us. This is the standard problem of causal inference, that is addressed by the matching procedure.

For this, we exploit the exogenous variation in the implementation of the scheme across time and space, as described in Section 2, and a matching approach to create a control group from which to estimate $E\left(Y^{0} \mid \mathrm{AES}=1\right)$. Non-participants who ultimately became participants are good candidates because data about their use of herbicides, collected one year before they entered the scheme, is available and because they are likely to have similar characteristics to early participants. Take the example of the AES impact in 2011, which is defined as follows:

$$
\mathrm{ATT}_{2011}=E\left(\mathrm{Y}_{2011}^{1} \mid \mathrm{AES}_{2011}=1, X\right)-E\left(\mathrm{Y}_{2011}^{0} \mid \mathrm{AES}_{2011}=0, \mathrm{AES}_{2012}=1, X\right)
$$

where $X$ is a vector of pre-treatment observable factors. The estimator implied by Equation 2 is simply the difference between two sample means: the average amount of herbicides used by winegrowers who were participants in 2011 and the average amount of herbicides used in 2011 by their matched counterparts, similar in terms of $X$, but who had to wait until 2012 to participate in the AES.7

For the identification of the ATT to be valid, we must make a second assumption, known as the Stable Unit Treatment Value Assumption (SUTVA), which requires that the treatment received by a subject does not alter the outcome for other subjects (Rubin, 1978). The SUTVA fails if, for example, the quantity of herbicides used by farmers in late approved catchments has been influenced by the implementation of the scheme in early approved catchments. If the group of winegrowers participating in the scheme in later-approved catchments has indeed reduced its average use of herbicides by anticipation of the AES, then using them as a control group would lead to underestimation of the impact of the scheme on early participants. In that case, we would measure the minimum impact of the scheme. Notice however that it is very unlikely that farmers begin to reduce herbicide use more than one year before the launch of the scheme on the catchment area where they are located.

\subsection{Estimators}

We use matching estimators, which address the selection bias caused by observable characteristics by comparing the TFI of current participants with those of observationally-identical matched future-participants. More specifically, we use the nearest-neighbor matching estimator (Abadie et al., 2004), and the kernel-based matching estimator (Leuven and Sianesi, 2003).

\footnotetext{
${ }^{7}$ Similarly, the AES impact in 2012, $\mathrm{ATT}_{2012}$, can be written as follows:

$$
\mathrm{ATT}_{2012}=E\left(\mathrm{Y}_{2012}^{1} \mid \mathrm{AES}_{2012}=1, X\right)-E\left(\mathrm{Y}_{2012}^{0} \mid \mathrm{AES}_{2012}=0, \mathrm{AES}_{2013}=1, X\right)
$$

The estimator implied by Equation 3 is the difference between the average amount of herbicides used by winegrowers who were participants in 2012 and the average amount of herbicides used in 2012 by their matched counterparts, similar in terms of $X$, but who had to wait until 2013 to participate in the AES.
} 
The general form of the matching estimator is:

$$
E\left(y^{1}-y^{0} \mid \mathrm{AES}=1\right)=\frac{1}{n_{1}} \sum_{i \in I_{1} \cap S_{P}}\left(y_{i}^{1}-E\left(y_{i}^{0} \mid \mathrm{AES}=1, X_{i}\right)\right)
$$

with

$$
E\left(y_{i}^{0} \mid \mathrm{AES}=1, X_{i}\right)=\sum_{j \in I_{0}} \lambda_{i j} y_{j}^{0}
$$

where $I_{1}$ denotes the group of treated farmers, $I_{0}$ denotes the group of untreated farmers, $n_{1}$ is the number of treated farmers in $I_{1} . S_{P}$ denotes the common support, or the subset of treated farmers for whom the density of observationally identical untreated farmers is higher than some cut-off level (Todd, 2008). Matching estimators differ in how matched untreated farmers are selected through the matching procedure. This difference is driven by the weights $\lambda_{i j}$ that we assign to potential matches given their characteristics $X$.

It is important that the covariates $X$ used for the matching procedure are not affected by the treatment (Imbens, 2004), which is why we utilize 2009 values from the French Agricultural Census. Moreover, we also apply the matching procedure to the summary statistic $\operatorname{Pr}\left(\mathrm{AES}_{i}=\right.$ $1 \mid X_{i}$ ), also called the propensity score (Rosenbaum and Rubin, 1983) 8

The nearest-neighbor matching estimator used in the analysis matches each treated farmer to the closest untreated farmer or the two closest untreated farmers according to the vector $X \unlhd^{9}$ Following Abadie et al. (2004), the matching procedure allows individual observations to be used as a match more than once. Compared with matching without replacement, this method generally lowers the bias but increases the variance. With kernel matching estimator, all untreated farmers are matched to each treated farmer, with the closest matches having a large value for $\lambda$ and the most distant matches having a close-to-zero value for $\lambda$.

We use the asymptotically-consistent estimator of the variance of the nearest-neighbour matching estimator allowing for heteroskedastic errors provided by Abadie and Imbens (2006), and we implement a bootstrap procedure of 500 repetitions in order to generate an estimator of the variance of the kernel matching estimator.

Finally, we generate an estimate of the ATT by running Ordinary Least Squares regression (OLS) of the TFI on the treatment variable AES, controlling for the pre-treatment variables $X$. In addition to the assumption of linearity, this requires us to assume that the gain associated with the AES is constant across $X$, meaning that the impact of the program is the same for all informed farmers. Note that the matching approach outperforms the OLS since it does not

\footnotetext{
${ }^{8}$ Matching on the set of observed covariates $X$ thus means that we look at the smallest distance between two vectors $X$, while matching on the propensity score means that we look at the smallest distance between two values of propensity score.

9ustin 2010 recommends that, in most settings, researchers match either one or two untreated subjects to each treated subject when using propensity-score matching. In the case of propensity score matching, pairs of treated and untreated subjects may be formed so that propensity scores differ by at most a pre-specified amount, the caliper width. In our case it appeared that the choice of caliper width had a negligible impact on the estimates so we decided not to use any caliper.
} 
require specifying the functional form of the outcome equation and relaxes the assumption of constant additive treatment effects across individuals. We run OLS regressions as a robustness check only.

\subsection{Matching procedure}

To estimate the ATT effect in 2011, we apply the matching procedure to the group of farmers who entered the scheme in 2010 (considered as treated farmers in 2011) using farmers who entered the scheme in 2011 or 2012 as untreated farmers in 2011. As explained before, farmers willing to participate in the AES have to send in an application form by May. Given that it is common practice to apply herbicides on vineyards well before May, it is reasonable to question whether farmers who entered the AES in year 2011 should actually be considered as treated or as untreated in year 2011 in the analysis. To check this, we compare the 2011 mean value of the TFI in the subgroup of farmers who entered the AES in May 2011 to the 2011 mean value of the TFI in the subgroup of farmers who entered in May 2012. The results show that the TFI does not differ significantly across groups. We conclude that farmers who entered the AES in year 2011 did not change their practices before the contract is signed and can be considered as untreated in year 2011.

Conditional probabilities for participating in the scheme (or propensity scores) are computed by estimating a probit model which includes all of the aforementioned covariates $X$, and where the dependent variable takes on the value of one if the farmer participated in the AES at least one year between 2010 and 2013 and zero if he never joined the scheme. To estimate this model, we thus add to the database a subset of winegrowers who were eligible for the AES but who decided not to participate in the scheme. We select a subset of those eligible farmers by taking all farmers located in the municipalities where a participant can be found. Those farmers had the opportunity to enter the scheme but intentionally decided not to do it, which make them very different from participants and thus constitute a relevant group for the prediction of the probability of being participant ${ }^{10}$ Given the estimates from the probit model, we then compute the propensity scores for the subset of farmers who will be used in the impact analysis (participants and future participants). Figure 2 indeed shows that densities in both groups are high enough for a wide range of propensity scores, meaning that the matching procedure is likely to perform well.

We then compare the extent of balancing between the two groups before and after the matching procedure. We calculate the normalized differences in covariate means between treated farmers and untreated farmers, before and after matching. The normalized difference

\footnotetext{
${ }^{10}$ Never-participants are useful only to compute propensity scores of current and future participants. Indeed, computing propensity scores requires a sample including not only individuals with a high chance of participating (i.e. farmers who will participate at some point in time) and individuals with a low chance of participating given their 2009-characteristics (i.e. farmers who will never participate). Never-participants are too different from current and future participants to be taken as a valid control group, even after conditioning on pre-treatment characteristics.
} 
is the difference in means between the two groups considered divided by the square root of the sum of variances for both groups, and is the most commonly accepted diagnostic used to assess covariate balance (Rosenbaum and Rubin, 1985, Stuart, 2010, Alix-Garcia, Sims, and Yañez-Pagans, 2015; Jayachandran et al. 2017). Table2 displays the results. In almost all cases, the sample differences in the raw data (Column. 4) exceed those after matching (Column. 5). Moreover, all the normalized differences after matching are below the suggested rule of thumb of 0.25 standard deviations (Imbens and Wooldridge, 2009), except the variable measuring age with a difference of 0.27 standard deviations. We conclude that the process of matching creates a high degree of balance between the treatment and control samples that are used in the estimation procedure.

We follow exactly the same procedure to estimate the impact of the AES in 2012. Specifically, we apply the matching procedure to the group of farmers who entered the scheme in 2010 or 2011 (considered as treated farmers in 2012) and the group who entered the scheme in 2012 or 2013 (considered as untreated in 2012). As for the $\mathrm{ATT}_{2011}$, we compute the propensity scores and find that densities in both groups are high enough for a wide range of propensity scores (Figure 3). We then calculate the normalized differences in covariate means between treated farmers and untreated farmers, before and after matching (see Table 5) and find that almost all the normalized differences after matching are below the suggested rule of thumb of 0.25 standard deviations (except the variable measuring age and the variable measuring the use of particular cellars but these differences remain small). We conclude again that the matching procedure performs well in eliminating potential sources of bias.

\section{Results}

\subsection{Impact of the AES in 2011 and 2012}

The first column of Table 3 gives the estimated ATT in 2011 from the matching estimators and the OLS regression. The results appear remarkably stable, with a negative difference in TFI between treated and control groups of -0.29 points using the smallest significant impact estimator, which is the one-nearest-neighbour estimator based on vector $X$, and -0.54 points using the largest significant impact estimator, which is the propensity score one-nearest neighbour matching estimator. Taking the smallest ATT and given that the average TFI equals 0.48 in the treated group, it means that the quantity of herbicides used by participants in the scheme in 2011 would have been $0.77(0.48+0.29)$ in the absence of the AES. Put differently, the quantity of herbicides used by participants in the scheme in 2011 is about 38 percent $(0.29 / 0.77)$ below the quantity that would have been used without the scheme. Taking the largest impact estimator, it is about 53 percent.

We test the sensitivity of our findings by using an approach that determines how strongly an unmeasured variable must influence the selection process in order to undermine the results of 
the matching analysis (DiPrete and Gangl, 2004, Rosenbaum, 2002). This test assumes that two farmers with the same observed characteristics may differ in the odds of participating in the AES by at most a factor of $\Gamma$, referred to as unobserved bias. We search the critical levels of $\Gamma$ at which the estimated ATT would become insignificant (at a 5 percent significance level). The results are displayed in first column of Table 4 . It indicates that, depending on the matching estimator considered, the critical value for $\Gamma$ ranges between 1.4 and 4 for the estimates of $A_{T T} T_{2011}$. Taking the smallest value found for $\Gamma$ (1.4), this means that two farmers who have the same observable characteristics $X$ would have to differ in their odds of scheme participation by a factor of 1.4 for the $\mathrm{ATT}_{2011}$ estimated with the matching procedure to become insignificant. We can thus conclude that, even though unobservable factors may explain part of being a participant in the AES, it is very unlikely that they would influence the odds of participation to such a large extent. We are thus confident that our identification strategy performs well.

Estimates of the impact of the AES in 2012 are displayed in the second column of Table 3 . The estimated ATT range between -0.33 and -0.46 points. Taking the smallest impact estimator, which is the kernel matching estimator and given that the average TFI equals 0.45 in the treated group, it means that the quantity of herbicides used by participants in the scheme in 2012 would have been $0.78(0.45+0.33)$ in the absence of the AES. Put differently, the quantity of herbicides used by participants in the scheme in 2012 is about 42 percent $(0.33 / 0.78)$ below the quantity that would have been used without the scheme. Taking the largest impact estimator, it is about 50 percent.

\subsection{Impact of the "zero herbicide between the rows" option}

Next, we turn to the impact analysis of one specific option of the AES, the so-called "zero herbicide between the rows" option, for which the sample size is large enough to allow specific investigation (81 farmers in 2011 and 92 farmers in 2012). This option is interesting because it is both the most frequently chosen as well as the least stringent among the options that target herbicide use - characteristics which are probably related. Indeed, although participants commit to use no herbicides between the rows, they have no constraints on the quantity of herbicides used underneath the rows.

Results of the estimates are displayed in Columns 3 and 4 of Table 3 . In 2011, the average TFI in the treated group ranges between 0.23 and 0.41 points below the average TFI in the control group. Given that the average TFI equals 0.70 in the treated group, this indicates that the quantity of herbicides used by participants in the scheme in this specific AES in 2011 ranges between 25 percent $(0.23 /(0.70+0.23))$ and 37 percent $(0.41 /(0.70+0.41))$ below the quantity that would have been used without the scheme. This is consistent with what could be expected for this measure, given that farmers who commit to not applying herbicides between vine rows are expected to reduce the quantity used by two third, as the space between vine rows is roughly twice as wide as the vine row. 
The story is very different in 2012, as the ATT does not appear statistically different from zero (Column 4 of Table 3). Indeed, as the mean TFI in the control group approaches the mean TFI in the treated group in 2012 (0.79), the impact of the AES on herbicide use becomes statistically nil. These results are in line with rainfall data for the years under study, which indicates higher weed pressure in 2011 than in 2012 due to higher rainfall in 2011 than in 2012. Indeed, the cumulative annual rainfall in the Languedoc-Roussillon region in 2011 was $955 \mathrm{~mm}$ while it was $724 \mathrm{~mm}$ only in 2012 according to Météo France ${ }^{11}$ Altogether, these findings suggest that the impact of this specific AES is weaker when weed pressure is low. In the particularly dry years, like in 2012, participants in this measure would have used approximately the same quantity of herbicides without any payment.

\subsection{Robustness checks}

As stressed just before, the quantity of herbicides used is expected to be higher during rainy years than during dry years, all other determinants being equal, because of the higher weed pressure that rainfall generates. One concern with our main findings is thus that estimates are driven by geographical differences across areas. Indeed, when comparing average levels of TFI among participants and future participants, to some extent we compare farmers located in the eastern zone of the region under study to farmers located in the western zone.

In order to avoid potential bias in the estimate of the impact of the AES that could arise due to spatial variability in meteorological characteristics of the study region, we thus perform the estimations by focusing on the subset of farmers located in the Eastern area of the region, who are very close to each other geographically and who constitute a large enough sample to ensure accurate results. $\sqrt{12}$ In doing so, the sample size falls to 89 farmers in 2011 and 94 farmers in 2012. Results of the estimates of $\mathrm{ATT}_{2011}$ and $\mathrm{ATT}_{2012}$ are displayed in Columns 1 and 2 of Table 6 . They appear very similar to those obtained from the initial sample in 2011, with an impact on participants ranging between 49 and 55 percent below the counterfactual TFI in 2011, while they appear slightly smaller in 2012 with an impact ranging between 31 percent and 40 percent in 2012. We conclude that the data we use from western areas do not bias the estimates in 2011. On the contrary, they may slightly pull the estimated impact downwards in 2012.

Finally, we run the same estimations on a sample in which farmers who engaged in organic farming schemes are excluded because we suspect that they may drive previous estimates. Results are displayed in Columns 3 and 4 of Table 6. They appear very similar to those obtained from the initial sample in 2011, with an impact on participants ranging between 42 and 54 percent below the counterfactual level of TFI. On the contrary, they appear slightly smaller than

\footnotetext{
${ }^{11}$ Figures are available on the site of Météo France

${ }^{12}$ Further East, in Gard county, are the territories of Malaven, Camp de Cesar, and Briancon. Farmers in these areas are not separated by more than $40 \mathrm{~km}$. We were not able to add the geographical location of farmers in the matching procedure as an additional covariate because the control group lacks farmers located in the western area of the region. Consequently we are not able to match treated farmers to untreated farmers both leaving in the Western area, the matching procedure would fail to find good matches in this area.
} 
those obtained from the initial sample in 2012, with an impact ranging between 26 percent and 34 percent only. This suggests that the small number of farmers who were engaged in organic farming schemes may, at least partly, drive the main result we estimated in 2012.

\section{Conclusions}

The main results of our analysis suggest that the AES options targeting the reduction of herbicide use in French vineyards had a significant impact on participants' practices. We show that the quantity of herbicides used by participants in the scheme in 2011 ranges from 38 to 53 percent below what they would have used without the scheme, and 42 to 50 percent in 2012. Overall, these results are robust to various estimators, robustness checks, and a sensitivity analysis.

We moreover show that the least demanding but most adopted AES option - "zero herbicide between the vine rows" - has a significant impact on herbicide use in 2011, but no significant impact in 2012. This suggests that least demanding AES options are effective in avoiding pollution peaks when weed pressure is high (as in 2011), whereas more demanding AES options guarantee an overall reduction in herbicide use even during easy farming years in which less weed pressure is experienced (as in 2012). This however also suggests the presence of windfall effects when weed pressure is low, which tend to decrease the efficiency of the program by using resources to pay for practices that would have been adopted anyway.

Though additional work is necessary to measure the impact of the scheme on overall water quality within the affected watersheds, our analysis constitutes a first step in this direction by measuring the impact of the schemes on farmers' use of herbicides at the field level. Obviously, measuring the effect of the scheme on water quality would require scaling-up our results to the farm and then watershed levels, coupling our analysis with hydro-ecological models. At this scale the actual impact of the scheme on water quality would largely depend on participation rates, the location of participants in the watershed, physical characteristics of the enrolled plots (slope, runoff rate) and other sources of nonpoint source pollution in the watershed.

\section{References}

Abadie, A., D. Drukker, J.L. Herr, and G.W. Imbens. 2004. "Implementing matching estimators for average treatment effects in Stata.” Stata Journal 4:290-311.

Abadie, A., and G.W. Imbens. 2006. "Large Sample Properties of Matching Estimators for Average Treatment Effects.” Econometrica 74:235-267.

Agreste. 2012. "Pratiques phytosanitaires dans la viticulture en 2010 : Moins de désherbants dans les vignes.” Primeur 288. 
—. 2011. "Recensement Agricole 2010 : Languedoc- Roussillon, premières tendances." Agreste Données, pp. .

Aker, J.C. 2010. "Information from Markets Near and Far: Mobile Phones and Agricultural Markets in Niger." American Economic Journal: Applied Economics 2:46-59.

Alix-Garcia, J.M., K.R.E. Sims, and P. Yañez-Pagans. 2015. "Only One Tree from Each Seed? Environmental Effectiveness and Poverty Alleviation in Mexico's Payments for Ecosystem Services Program." American Economic Journal: Economic Policy 7:1-40.

Arata, L., and P. Sckokai. 2016. "The Impact of Agri-environmental Schemes on Farm Performance in Five E.U. Member States: A DID-Matching Approach.” Land Economics 92:167-186.

Austin, P.C. 2010. "Statistical Criteria for Selecting the Optimal Number of Untreated Subjects Matched to Each Treated Subject When Using Many-to-One Matching on the Propensity Score." American Journal of Epidemiology 172:1092-1097.

Bruhn, M. 2013. "A tale of two species: Revisiting the effect of registration reform on informal business owners in Mexico." Journal of Development Economics 103:275 - 283.

Chabé-Ferret, S., and J. Subervie. 2013. "How much green for the buck? Estimating additional and windfall effects of French agro-environmental schemes by DID-matching." Journal of Environmental Economics and Management 65(1):12 - 27.

DiPrete, T.A., and M. Gangl. 2004. "Assessing Bias in the Estimation of Causal Effects: Rosenbaum Bounds on Matching Estimators and Instrumental Variables Estimation with Imperfect Instruments." Sociological Methodology 34:271-310.

Fraser, R. 2009. "Land Heterogeneity, Agricultural Income Forgone and Environmental Benefit: An Assessment of Incentive Compatibility Problems in Environmental Stewardship Schemes." Journal of Agricultural Economics 60:190-201.

Galiani, S., P. Gertler, and E. Schargrodsky. 2005. "Water for Life: The Impact of the Privatization of Water Services on Child Mortality." Journal of Political Economy 113:83-120.

Imbens, G.W. 2004. "Nonparametric Estimation of Average Treatment Effects Under Exogeneity: A Review." The Review of Economics and Statistics 86:4-29.

Imbens, G.W., and J.M. Wooldridge. 2009. "Recent developments in the econometrics of program evaluation." Journal of economic literature 47:5-86.

Jayachandran, S., J.d. Laat, E.F. Lambin, and C. Stanton. 2017. "Cash for Carbon: A Randomized Trial of Payments for Ecosystem Services to Reduce Deforestation.” Science, July, pp. (forthcoming). 
Jensen, R. 2007. “The Digital Provide: Information (Technology), Market Performance, and Welfare in the South Indian Fisheries Sector.” The Quarterly Journal of Economics 122:879-924.

Leuven, E., and B. Sianesi. 2003. "PSMATCH2: Stata module to perform full Mahalanobis and propensity score matching, common support graphing, and covariate imbalance testing." Statistical Software Components, Boston College Department of Economics.

Pingault, N., E. Pleyber, C. Champeaux, L. Guichard, and B. Omon. 2009. "Produits phytosanitaires et protection intégrée des cultures : l'indicateur de fréquence de traitement." Notes et Etudes socio-économiques 32:61-94.

Pufahl, A., and C.R. Weiss. 2009. "Evaluating the Effects of Farm Programmes: Results from Propensity Score Matching." European Review of Agricultural Economics 36:79-101.

Rosenbaum, P.R. 2002. Observational Studies, N. Y. 2nd ed. Springer-Verlag, ed.

Rosenbaum, P.R., and D.B. Rubin. 1985. "Constructing a Control Group Using Multivariate Matched Sampling Methods That Incorporate the Propensity Score.” The American Statistician 39:33-38.

—. 1983. "The Central Role of the Propensity Score in Observational Studies for Causal Effects." Biometrika 70:41-55.

Rubin, D.B. 1978. "Bayesian Inference for Causal Effects: The Role of Randomization.” The Annals of Statistics 6:34-58.

Stuart, E.A. 2010. "Matching methods for causal inference: A review and a look forward." Statistical Science?: A Review Journal of the Institute of Mathematical Statistics 25:1-21.

Todd, P.E. 2008. "Evaluating Social Programs with Endogenous Program Placement and Selection of the Treated." Elsevier, vol. 4, chap. 60, 1st ed., pp. 3847-3894.

Udagawa, C., I. Hodge, and M. Reader. 2014. "Farm Level Costs of Agri-environment Measures: The Impact of Entry Level Stewardship on Cereal Farm Incomes." Journal of Agricultural Economics 65:212-233.

Uthes, S., and B. Matzdorf. 2013. "Studies on Agri-environmental Measures: A Survey of the Literature.” Environmental Management 51:251-266. 


\section{Tables}

Table 1: Area enrolled in the scheme included in the sample, by AES option and by start year (ha)

\begin{tabular}{lcccccc} 
AES & 2010 & 2011 & 2012 & 2013 & Total & $\%$ \\
\hline phyto02 & 92.1 & 2.9 & 12.4 & 41.1 & 148.6 & 4 \\
phyto04 & 176.4 & 3.5 & 0.0 & 0.0 & 179.9 & 5 \\
phyto10 & 562.9 & 272.3 & 1840.8 & 197.7 & 2873.7 & 79 \\
couver03 & 0.0 & 0.0 & 17.8 & 0.0 & 17.8 & 0 \\
bioconv & 119.1 & 149.2 & 103.7 & 0.0 & 372.0 & 10 \\
biomaint & 0.0 & 0.0 & 37.7 & 0.0 & 37.7 & 1 \\
Total & 950.5 & 427.9 & 2012.4 & 238.9 & 3629.7 & 100 \\
\hline
\end{tabular}

Note: AES phyto02 refers to the suppression of herbicide use; AES phyto04 refers to the reduction in herbicides use by $40 \%$ of the regional standard; AES phyto10 refers to the suppression of herbicide use between the vine rows; AES couver03 refers to maintaining grass under-the-row; AES bioconv (resp. biomaint) refers to the conversion to (resp. maintaining of) organic wine growing. 


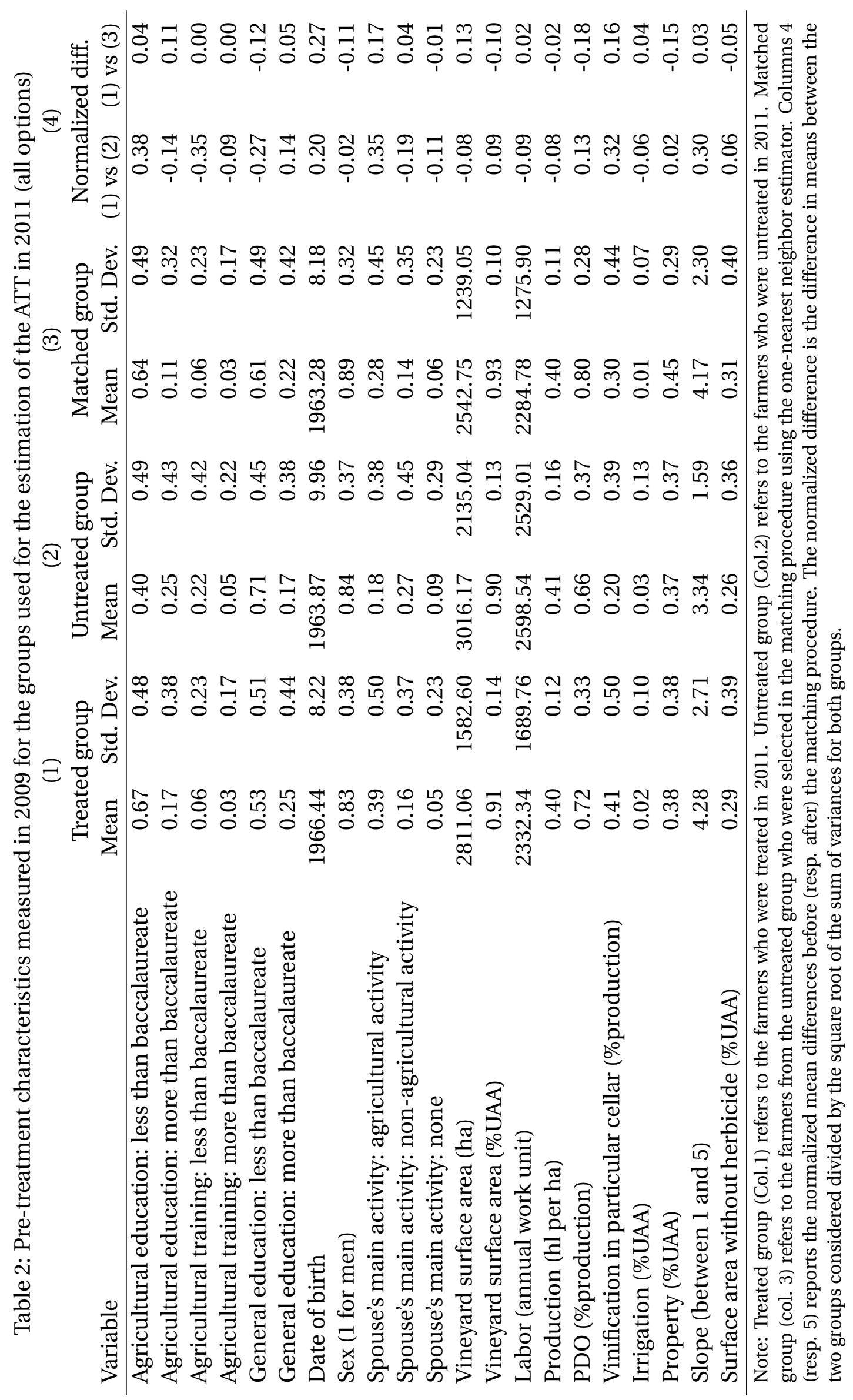


Table 3: Average Treatment Effects

\begin{tabular}{lrrrrrrr} 
& \multicolumn{3}{c}{ All options } & \multicolumn{3}{c}{ Between-the-rows } \\
& \multicolumn{2}{c}{2011} & 2012 & 2011 & 2012 \\
\hline Estimator & -0.29 & $* *$ & -0.34 & $* *$ & -0.41 & $* * *$ & -0.09 \\
& 0.11 & & 0.16 & & 0.15 & & 0.18 \\
One Nearest Neighbour (X) & -0.54 & $* * *$ & -0.39 & $* * *$ & -0.26 & $*$ & -0.07 \\
& 0.16 & & 0.12 & & 0.14 & & 0.11 \\
Two Nearest Neighbours (X) & -0.43 & $* * *$ & -0.46 & $* * *$ & -0.37 & $* *$ & -0.18 \\
& 0.10 & & 0.12 & & 0.18 & & 0.16 \\
Two Nearest Neighbours (pscore) & -0.50 & $* * *$ & -0.35 & $* * *$ & -0.23 & $* *$ & -0.05 \\
& 0.12 & & 0.11 & & 0.11 & & 0.09 \\
Kernel regression & -0.48 & $* * *$ & -0.33 & $* * *$ & -0.31 & $* *$ & -0.08 \\
& 0.10 & & 0.09 & & 0.13 & & 0.09 \\
OLS (X) & -0.43 & $* * *$ & -0.33 & $* * *$ & -0.32 & $* * *$ & -0.25 \\
& 0.11 & & 0.13 & & 0.10 & & 0.14 \\
\hline Average TFI in treated group & 0.48 & & 0.45 & & 0.70 & & 0.79 \\
\hline
\end{tabular}

Note: Three asterisks ${ }^{* * *}\left(\right.$ resp. ${ }^{* *},{ }^{*}$ ) denote rejection of the null hypothesis of no impact at the $1 \%$ (resp. 5\%, 10\%) significance level. One (resp. two) Nearest Neighbour (X) refers to the nearest neighbor estimator using one (resp. two) matched observations and the vector X. Standard errors in italics below coefficients.

Table 4: Magnitude of the unobserved bias for a 5\% significance level

Magnitude of $\Gamma$

\begin{tabular}{lcc} 
Estimator & 2011 & 2012 \\
\hline One Nearest Neighbour (X) & 1.4 & 1.9 \\
One Nearest Neighbour (pscore) & 2.9 & 1.9 \\
Two Nearest Neighbours (X) & 2.6 & 2.6 \\
Two Nearest Neighbours (pscore) & 3 & 2 \\
Kernel regression & 4 & 2.7 \\
\hline This tables gives the magnitude of the unobserved
\end{tabular}
bias $(\Gamma)$ that would explain the estimated ATT in 2011 and 2012, using various estimators. The magnitude of $\gamma$ was computed using the procedure provided by DiPrete and Gangl (2004) based on the approach of Rosenbaum (2002). 


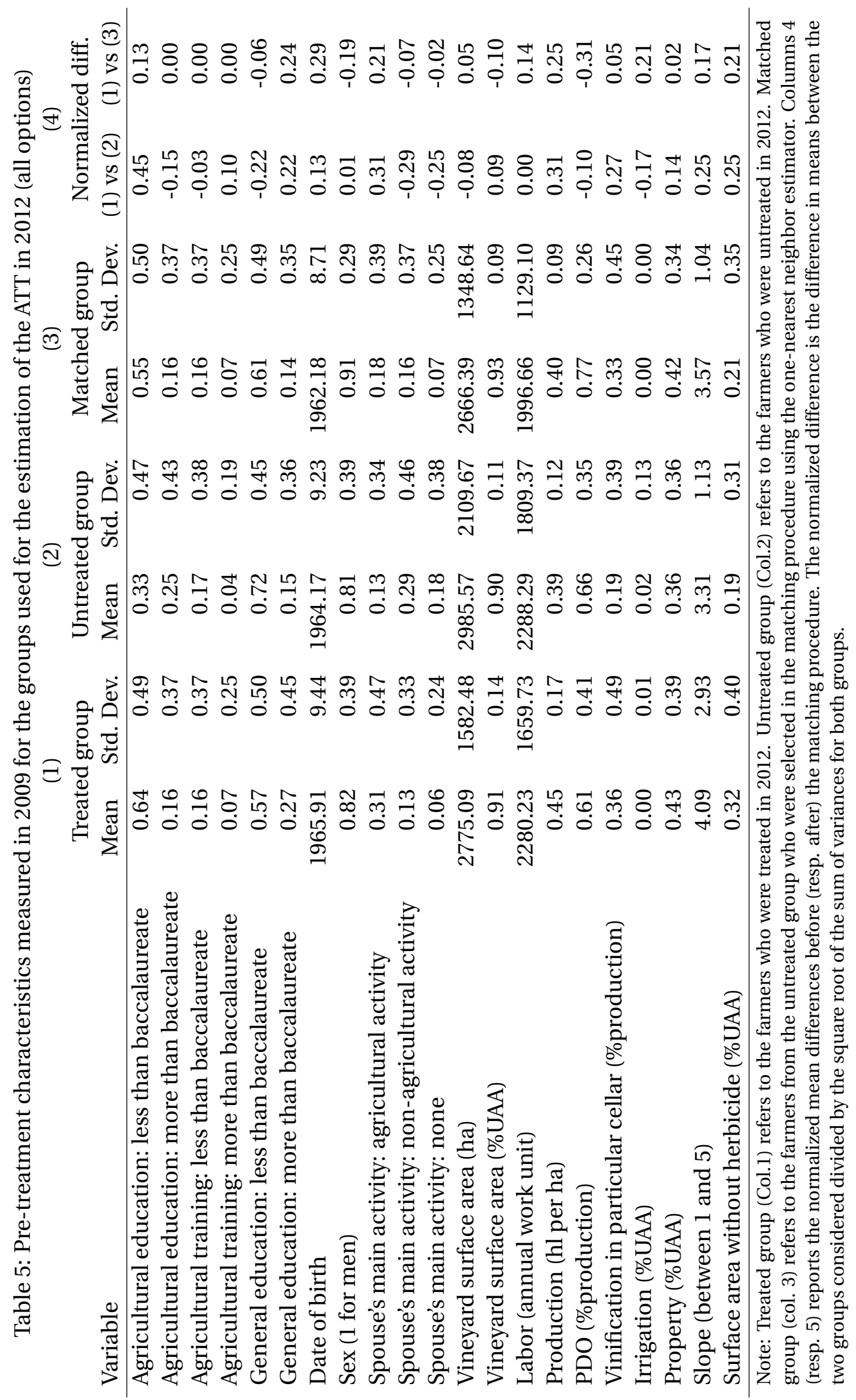


Table 6: Average Treatment Effects - Robustness checks

\begin{tabular}{|c|c|c|c|c|c|c|c|c|}
\hline \multirow{3}{*}{$\begin{array}{l}\text { Estimator } \\
\text { One Nearest Neighbour (X) }\end{array}$} & \multicolumn{4}{|c|}{ Excluding western area } & \multicolumn{4}{|c|}{ Excluding organic farmers } \\
\hline & \multicolumn{2}{|c|}{2011} & \multicolumn{2}{|c|}{2012} & \multicolumn{2}{|c|}{2011} & \multicolumn{2}{|c|}{2012} \\
\hline & -0.59 & $* * *$ & -0.26 & & -0.40 & $* * *$ & -0.19 & \\
\hline & 0.12 & & 0.20 & & 0.13 & & 0.14 & \\
\hline \multirow[t]{2}{*}{ One Nearest Neighbour (pscore) } & -0.62 & $* * *$ & -0.23 & * & -0.65 & $* * *$ & -0.31 & ** \\
\hline & 0.17 & & 0.14 & & 0.15 & & 0.12 & \\
\hline \multirow[t]{2}{*}{ Two Nearest Neighbours (X) } & -0.57 & $* * *$ & -0.34 & $* *$ & -0.45 & $* * *$ & -0.27 & $* *$ \\
\hline & 0.13 & & 0.14 & & 0.10 & & 0.13 & \\
\hline \multirow[t]{2}{*}{ Two Nearest Neighbours (pscore) } & -0.58 & $* * *$ & -0.26 & $* *$ & -0.54 & $* * *$ & -0.22 & $* *$ \\
\hline & 0.12 & & 0.11 & & 0.12 & & 0.10 & \\
\hline \multirow[t]{2}{*}{ Kernel regression } & -0.57 & $* * *$ & -0.31 & $* * *$ & -0.50 & $* * *$ & -0.22 & ** \\
\hline & 0.10 & & 0.09 & & 0.09 & & 0.09 & \\
\hline \multirow[t]{2}{*}{ OLS (X) } & -0.49 & $* * *$ & -0.34 & $* * *$ & -0.52 & $* * *$ & -0.32 & $* *$ \\
\hline & 0.14 & & 0.13 & & 0.12 & & 0.13 & \\
\hline Average TFI in treated group & 0.50 & & 0.52 & & 0.55 & & 0.62 & \\
\hline
\end{tabular}

Note: Three asterisks ${ }^{* * *}\left(\right.$ resp. ${ }^{* *},{ }^{*}$ ) denote rejection of the null hypothesis of no impact at the $1 \%$ (resp. $5 \%, 10 \%$ ) significance level. One (resp. two) Nearest Neighbour (X) refers to the nearest neighbor estimator using one (resp. two) matched observations and the vector X. Standard errors in italics below coefficients. 


\section{Figures}

Figure 1: Location of surveyed farmers

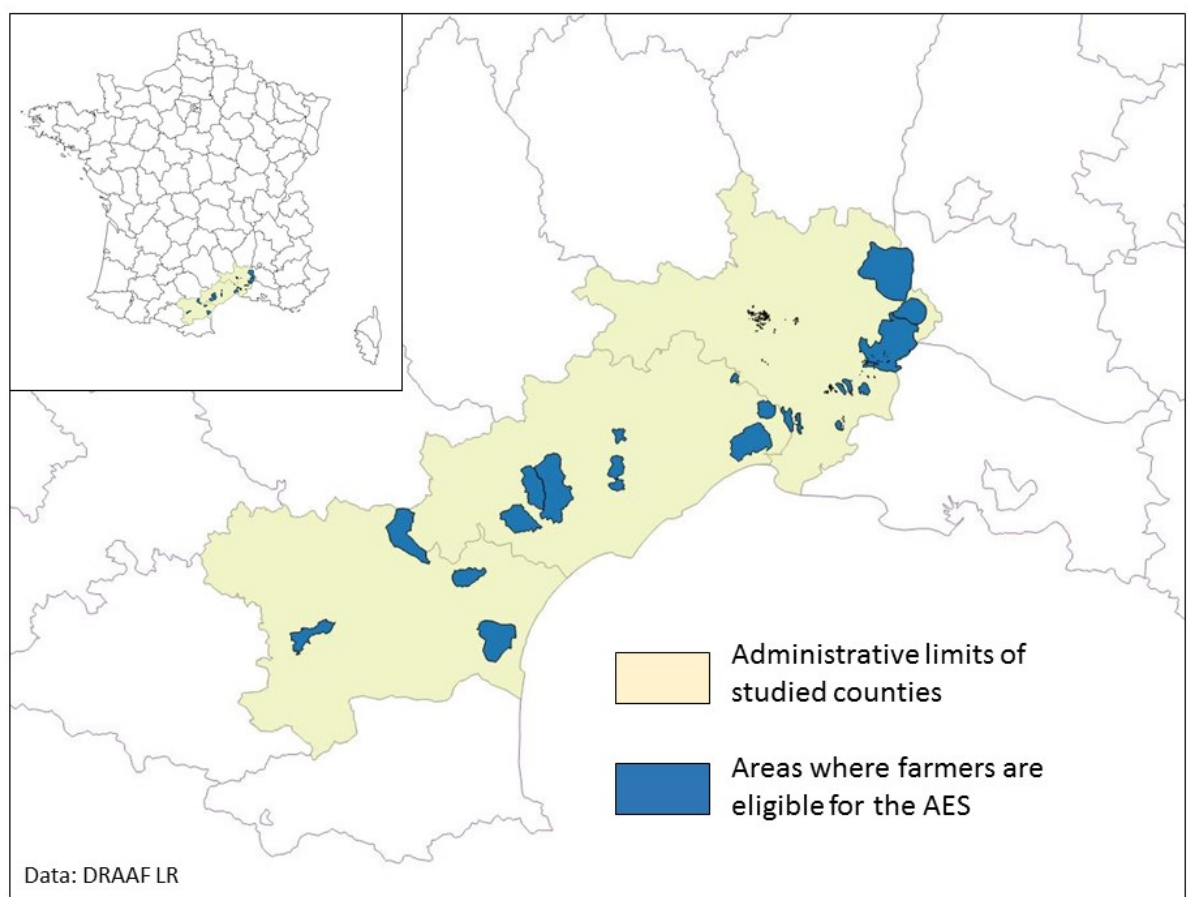

Figure 2: Density of propensity scores by group - ATT in 2011 (all options)

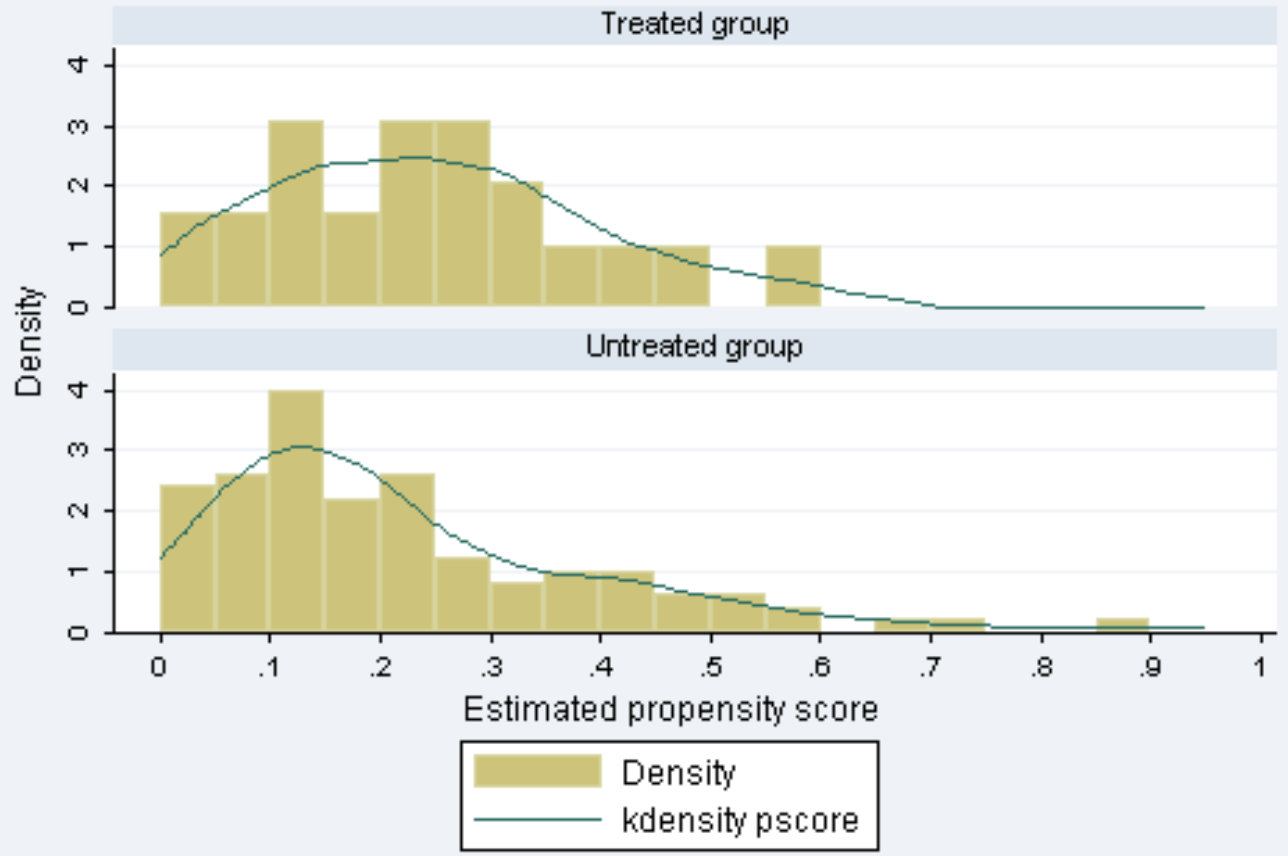


Figure 3: Density of propensity scores by group - ATT in 2012 (all options)

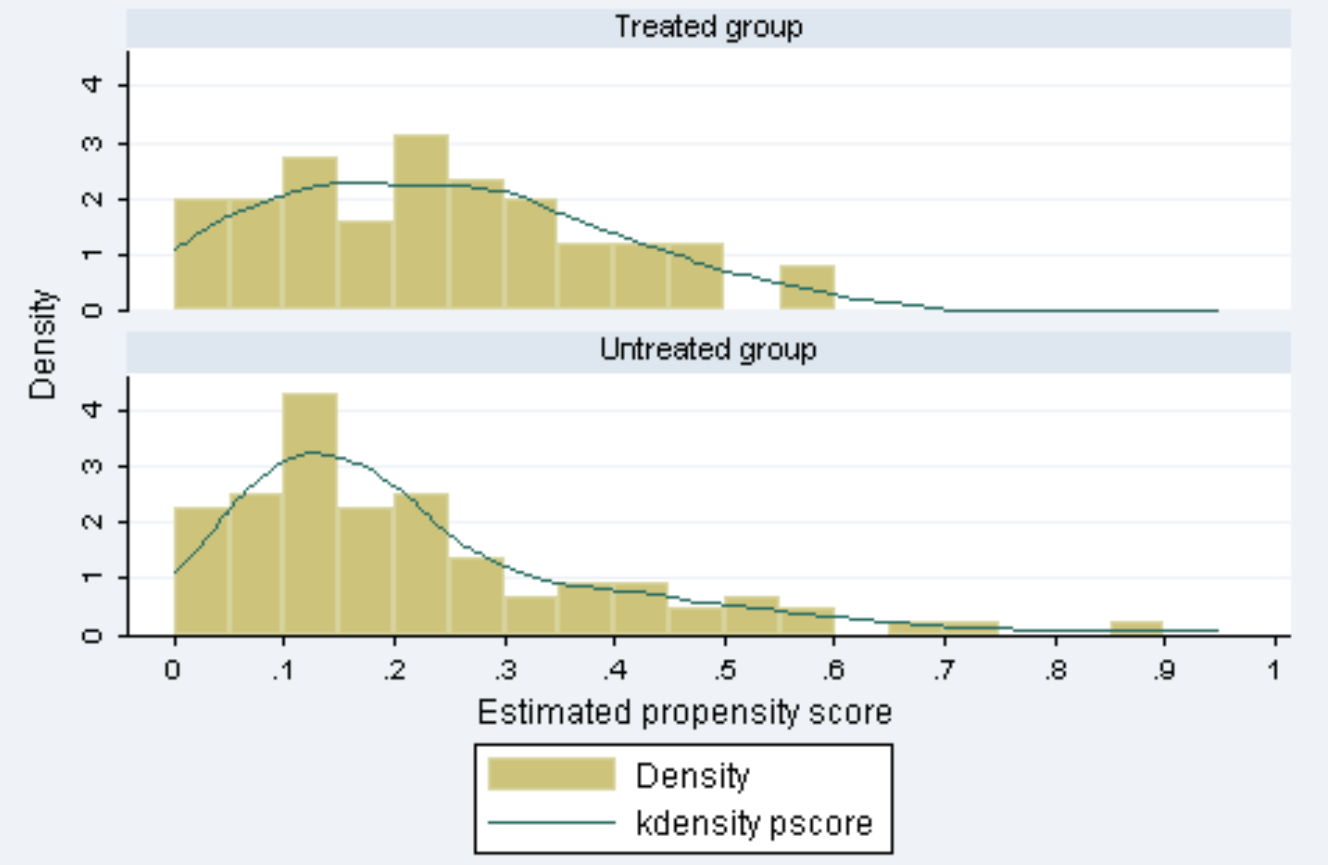

